\title{
Age Over 80 is a Possible Risk Factor for Postoperative Morbidity After a Laparoscopic Resection of Colorectal Cancer
}

\author{
Taekhyun Kang, Hyung Ook Kim, Hungdai Kim, Ho-Kyung Chun, Won Kon Han, Kyung Uk Jung \\ Department of Surgery, Kangbuk Samsung Hospital, Sungkyunkwan University of School of Medicine, Seoul, Korea
}

Purpose: With extended life expectancy, the mean age of patients at the time of diagnosis of colorectal cancer and its treatment, including radical resection, is increasing gradually. We aimed to evaluate the impact of age on postoperative clinical outcomes after a laparoscopic resection of colorectal cancers.

Methods: This is a retrospective review of prospectively collected data. Patients with primary colorectal malignancies or premalignant lesions who underwent laparoscopic colectomies between January 2009 and April 2013 were identified. Patients were divided into 6 groups by age using 70, 75, and 80 years as cutoffs: younger than 70,70 or older, younger than 75,75 or older, younger than 80 , and 80 or older. Demographics, pathological parameters, and postoperative clinical outcomes, including postoperative morbidity, were compared between the younger and the older age groups.

Results: All 578 patients underwent a laparoscopic colorectal resection. The overall postoperative complication rate was $21.1 \%(n=122)$. There were 4 cases of operative mortality $(0.7 \%)$. Postoperative complication rates were consistently higher in the older groups at all three cutoffs; however, only the comparison with a cutoff at 80 years showed a statistically significant difference between the younger and the older groups.

Conclusion: Age over 80 is a possible risk factor for postoperative morbidity after a laparoscopic resection of colorectal cancer.

\section{Keywords: Colonic neoplasms; Aged; Laparoscopy}

\section{INTRODUCTION}

Colorectal cancer is one of the most common malignancies not only in Western countries but also in Northeast Asia. It is the third most common cancer and the fourth leading cause of cancer-related death in the Republic of Korea, with about 25,700 new cases and 7,700 related deaths per year [1]. Cancer is a disease of elderly people, and its incidence increases with age because of the

Received: October 13,2015 • Accepted: November 5, 2015

Correspondence to: Kyung Uk Jung, M.D.

Department of Surgery, Kangbuk Samsung Medical Center, Sungkyunkwan University School of Medicine, 29 Saemunan-ro, Jongno-gu, Seoul 03181, Korea

Tel: +82-2-2001-8576, Fax: +82-2-2001-8360

E-mail: sahelgrean@gmail.com

(C) 2015 The Korean Society of Coloproctology

This is an open-access article distributed under the terms of the Creative Commons Attribution NonCommercial License (http://creativecommons.org/licenses/by-nc/3.0) which permits unrestricted noncommercial use, distribution, and reproduction in any medium, provided the original work is properly cited. accumulation of genetic errors. Today, the average life expectancy in many developed countries is more than 80 years. With this extended life expectancy, the mean age of patients at the time of diagnosis and treatment of colorectal cancers, including radical resection, is also increasing $[2,3]$.

With improvements in anesthesia, perioperative care, and surgical techniques, recent studies have shown similar rates of complications after major colorectal procedures in elderly patients compared with younger ones. Those studies suggested that age alone, without significant comorbidities, should not be considered as a contraindication for major colorectal surgery, especially in the era of laparoscopic surgery [4-7]. However, the cutoffs used for classifying 'elderly' vary between studies. Because no definite consensus exist as to what age 'elderly' indicates, authors have used a number of different thresholds ranging from 65 to 85 years in various studies. Patients older than 65 and those older than 85 represent entirely different age groups, so we cannot consider them as similar groups carrying the same degree of perioperative risk. Here, 
we aimed to evaluate the impact of age on postoperative clinical outcomes and to determine how being 'elderly' is a risk factor for complications after a laparoscopic resection of colorectal cancers by comparing younger and older groups with different cutoffs.

\section{METHODS}

This study was a retrospective review of prospectively collected data. Patients with primary colorectal malignancies or premalignant lesions who underwent a laparoscopic colorectal resection at Kangbuk Samsung Hospital between January 2009 were identified and included in the analysis. During the study period, 619 patients with primary colorectal malignancies or premalignant lesions underwent elective surgical procedures involving a colectomy. Patients who required emergency procedures were excluded. Among these, we excluded 26 patients who needed combined procedures on other organs (except for a cholecystectomy, an appendectomy, or a salpingo-oophorectomy), 9 patients who underwent a subtotal, a total, or a transverse colectomy (to avoid generating groups that were too small for analysis), and 6 patients who required 2 or more anastomoses at one time (Fig. 1). Then, we divided the patients into 6 groups on the basis of chronological age by using 70,75 , and 80 years as cutoffs: $<70$ years $(n=383)$ and $\geq 70$ years $(\mathrm{n}=195) ;<75$ years $(\mathrm{n}=480)$ and $\geq 75$ years $(\mathrm{n}=$ $98) ;<80$ years $(\mathrm{n}=547)$ and $\geq 80$ years $(\mathrm{n}=31)$.

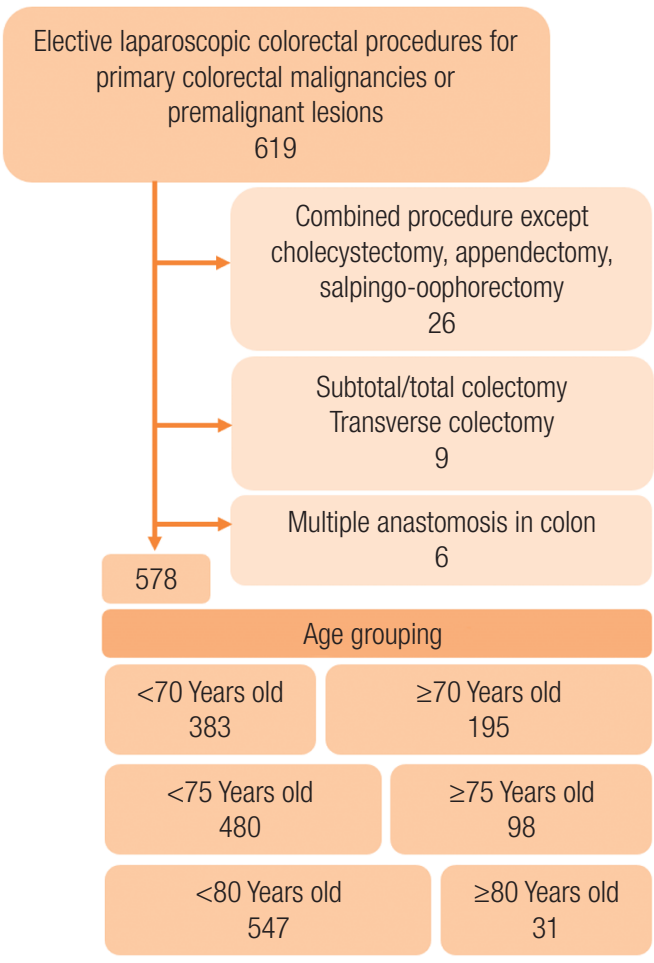

Fig. 1. Schema of patient selection and classification using three different age cutoffs for defining 'elderly'.
Confirmation of the pathology obtained by using a colonoscopic biopsy was completed for all patients before treatment. Pretreatment workups included a full colonoscopic examination, abdominopelvic computed tomography (CT), and chest CT or x-ray. Digital rectal examinations and rectal magnetic resonance imaging were conducted for those patients with rectal lesions. Wholebody positron emission tomography scanning was performed selectively in some patients. Bowel preparation was performed with a polyethylene glycol solution (2-4 L) on the day before surgery. Expert anesthesiologists determined the American Society of Anesthesiologists (ASA) score preoperatively. For antibiotic prophylaxis, second-generation cephalosporin was administered during the induction of anesthesia in all patients. All operations were performed by an experienced colorectal surgical team, according to the principles of radical surgery, and included an en bloc resection, adequate lymphadenectomy with ligation of the lymphovascular pedicles, and clear resection margins. A total mesorectal excision technique was used in cases with rectal lesions, even in palliative cases. Conversion to an open operation was defined as a vertical abdominal incision greater in size than that needed for specimen retrieval.

Patient demographics and perioperative clinical and pathologic parameters, including the details of the surgical procedure and the recovery of bowel function, were collected. Postoperative morbidity was defined as complications that required additional treatment or a prolonged hospital stay. The Clavien-Dindo classification [8] was used to grade the severity of morbidity. Operative mortality was defined as death within 30 days of surgery or inhospital death after operation.

The data were analyzed by using IBM SPSS Statistics ver. 20.0 (IBM Co., Armonk, NY, USA). Continuous variables are presented as the means \pm standard deviations and were analyzed by using the Mann-Whitney nonparametric $U$ test. Categorical variables are presented as the number (percentage) and were analyzed using the chi-square and Fisher exact tests. Univariate and multivariate logistic regression models were used to estimate the odds ratios (ORs) with 95\% confidence intervals (CIs) for postoperative morbidity. Results were considered to be statistically significant at $\mathrm{P}<0.05$.

\section{RESULTS}

Three hundred fifty-three men (61.1\%) and 225 women (38.9\%) were included in the study. Their mean age was $63.3 \pm 11.6$ years (range, 20-94 years), and the mean body mass index (BMI) was $23.7 \pm 3.4 \mathrm{~kg} / \mathrm{m}^{2}$ (range, $14.3-38.7 \mathrm{~kg} / \mathrm{m}^{2}$ ) at the time of surgery. All 578 patients underwent a laparoscopic colorectal resection with conventional laparoscopy adopting three to five access ports or a hand-assisted laparoscopy technique. Each technique was selected according to the surgeon's preference.

Comparison of the demographics and the clinical outcomes between the younger and the older groups, as defined by using the 
three thresholds described above, are listed in Table 1. Differences and similarities between the younger and the older groups were analogous to comparisons with different cutoffs. In all three comparative analyses, ASA score, the presence of comorbidity and the

Table 1. Demographic and clinical characteristics of the patients according to the different age cutoffs

\begin{tabular}{|c|c|c|c|c|c|c|c|c|c|}
\hline \multirow[b]{2}{*}{ Variable } & \multicolumn{3}{|c|}{ Cutoff age 70} & \multicolumn{3}{|c|}{ Cutoff age 75} & \multicolumn{3}{|c|}{ Cutoff age 80} \\
\hline & $\begin{array}{c}<70 \\
(n=383)\end{array}$ & $\begin{array}{c}\geq 70 \\
(n=195)\end{array}$ & P-value & $\begin{array}{c}<75 \\
(n=480)\end{array}$ & $\begin{array}{c}\geq 75 \\
(n=98)\end{array}$ & P-value & $\begin{array}{c}<80 \\
(n=547)\end{array}$ & $\begin{array}{c}\geq 80 \\
(n=31)\end{array}$ & P-value \\
\hline Age (yr) & $57.2 \pm 9.0$ & $75.4 \pm 4.9$ & $<0.001$ & $60.1 \pm 1.0$ & $79.1 \pm 4.3$ & $<0.001$ & $62.2 \pm 10.8$ & $84.3 \pm 3.9$ & 0.001 \\
\hline Female sex & $149(38.9)$ & $76(39.0)$ & 0.987 & $181(37.7)$ & $44(44.9)$ & 0.183 & $212(38.8)$ & $13(41.9)$ & 0.724 \\
\hline Body mass index $\left(\mathrm{kg} / \mathrm{m}^{2}\right)$ & $24.0 \pm 3.4$ & $23.0 \pm 3.3$ & 0.002 & $23.9 \pm 3.4$ & $22.6 \pm 3.3$ & $<0.001$ & $23.7 \pm 3.4$ & $22.2 \pm 2.4$ & 0.006 \\
\hline ASA score & & & $<0.001$ & & & $<0.001$ & & & $<0.001$ \\
\hline 1 & $167(43.6)$ & $28(14.4)$ & & $186(38.8)$ & $9(9.2)$ & & $194(35.5)$ & $1(3.2)$ & \\
\hline 2 & $174(45.4)$ & $102(52.3)$ & & $228(47.5)$ & $48(49.0)$ & & $263(48.1)$ & $13(41.9)$ & \\
\hline 3 & $42(11.0)$ & 65 (33.3) & & $66(13.8)$ & $41(41.8)$ & & $90(16.5)$ & $17(54.8)$ & \\
\hline Comorbidities, yes & $175(45.7)$ & $143(73.3)$ & $<0.001$ & $241(50.2)$ & 77 (78.6) & $<0.001$ & $294(53.7)$ & $24(77.4)$ & 0.001 \\
\hline No. of comorbidities & $0.7 \pm 0.9$ & $1.26 \pm 1.1$ & $<0.001$ & $0.8 \pm 1.0$ & $1.4 \pm 1.0$ & $<0.001$ & $0.8 \pm 1.0$ & $1.52 \pm 1.2$ & $<0.001$ \\
\hline Previous abdominal OP history, yes & 76 (19.8) & $37(19.0)$ & 0.803 & $91(19.0)$ & $22(22.4)$ & 0.427 & $107(19.6)$ & $6(19.4)$ & 0.978 \\
\hline Operation name & & & 0.081 & & & 0.554 & & & 0.073 \\
\hline Right hemicolectomy & $91(23.8)$ & $62(31.8)$ & & $124(25.8)$ & 29 (29.6) & & $139(25.4)$ & $14(45.2)$ & \\
\hline Left hemicolectomy & $22(5.7)$ & $6(3.1)$ & & $24(5.0)$ & $4(4.1)$ & & $28(5.1)$ & $0(0)$ & \\
\hline Anterior resection & $126(32.9)$ & $48(24.6)$ & & $151(31.5)$ & $23(23.5)$ & & $167(30.5)$ & $7(22.6)$ & \\
\hline Low anterior resection & $132(34.5)$ & $73(37.4)$ & & $167(34.8)$ & $38(38.8)$ & & $197(36.0)$ & $8(25.8)$ & \\
\hline Abdominoperineal resection & $12(3.1)$ & $6(3.1)$ & & $14(2.9)$ & $4(4.1)$ & & $16(2.9)$ & $2(6.5)$ & \\
\hline Laparoscopy method & & & 0.478 & & & 0.367 & & & 0.405 \\
\hline Conventional laparoscopy & $108(27.9)$ & $60(30.8)$ & & $135(28.1)$ & $32(32.7)$ & & $156(28.5)$ & $11(35.5)$ & \\
\hline Hand-assisted laparoscopy & $276(72.1)$ & $135(69.2)$ & & $345(71.9)$ & $66(67.3)$ & & $391(71.5)$ & $20(64.5)$ & \\
\hline
\end{tabular}

Values are presented as mean \pm standard deviation or number (\%).

ASA, American Society of Anesthesiologists; OP, operation.

Table 2. Clinical and pathologic parameters of the patients according to the different age cutoffs

\begin{tabular}{|c|c|c|c|c|c|c|c|c|c|}
\hline \multirow[b]{2}{*}{ Variable } & \multicolumn{3}{|c|}{ Cutoff age 70} & \multicolumn{3}{|c|}{ Cutoff age 75} & \multicolumn{3}{|c|}{ Cutoff age 80} \\
\hline & $\begin{array}{c}<70 \\
(n=383)\end{array}$ & $\begin{array}{c}\geq 70 \\
(n=195)\end{array}$ & P-value & $\begin{array}{c}<75 \\
(n=480)\end{array}$ & $\begin{array}{c}\geq 75 \\
(n=98)\end{array}$ & P-value & $\begin{array}{c}<80 \\
(n=547)\end{array}$ & $\begin{array}{c}\geq 80 \\
(n=31)\end{array}$ & P-value \\
\hline Operation time (min) & $140.7 \pm 41.8$ & $145.4 \pm 42.3$ & 0.154 & $140.8 \pm 41.4$ & $149.4 \pm 44.3$ & 0.066 & $142.2 \pm 42.1$ & $144.2 \pm 40.9$ & 0.560 \\
\hline Estimated blood loss (mL) & $148.5 \pm 213.8$ & $187.9 \pm 251.8$ & 0.425 & $157.0 \pm 226.7$ & $183.8 \pm 232.0$ & 0.398 & $158.5 \pm 225.1$ & $218.9 \pm 269.2$ & 0.604 \\
\hline Conversion, yes & $2(0.5)$ & $3(1.5)$ & 0.342 & $3(0.6)$ & $2(2.0)$ & 0.201 & $4(0.7)$ & $1(3.2)$ & 0.242 \\
\hline No. of retrieved lymph nodes & $23.3 \pm 12.9$ & $22.0 \pm 11.5$ & 0.405 & $23.1 \pm 12.6$ & $21.6 \pm 11.5$ & 0.249 & $22.9 \pm 12.6$ & $22.0 \pm 8.9$ & 0.631 \\
\hline Tumor size (cm) & $4.7 \pm 2.4$ & $5.1 \pm 2.3$ & 0.025 & $4.7 \pm 2.4$ & $5.4 \pm 2.2$ & 0.005 & $4.8 \pm 2.4$ & $6.1 \pm 2.4$ & 0.009 \\
\hline TNM stage ${ }^{a}$ & & & $0.010^{\mathrm{b}}$ & & & 0.064 & & & 0.142 \\
\hline Tis & $2(0.5)$ & $3(1.6)$ & & $4(0.8)$ & $1(1.1)$ & & $5(0.9)$ & $0(0)$ & \\
\hline । & 85 (22.5) & 31 (16.3) & & $102(21.6)$ & $14(14.9)$ & & $114(21.2)$ & $2(6.9)$ & \\
\hline$\|$ & $95(25.2)$ & $76(40.0)$ & & $137(29.0)$ & $34(36.2)$ & & $160(29.7)$ & $11(37.9)$ & \\
\hline III & $165(43.8)$ & $73(38.4)$ & & $194(41.0)$ & $44(46.8)$ & & $222(41.3)$ & $16(55.2)$ & \\
\hline IV & $30(8.0)$ & $7(3.7)$ & & $36(7.6)$ & $1(1.1)$ & & $37(6.9)$ & $0(0)$ & \\
\hline
\end{tabular}

Values are presented as mean \pm standard deviation or number $(\%)$.

aThe patients who had colorectal malignancies other than adenocarcinoma (e.g., lymphoma) were not included ( $n=11)$; ${ }^{b}$ Modified P-value. 
numbers of comorbidities were significantly different between the younger and the older groups. The BMI was consistently significantly lower in the older groups. Other demographic features were similar between the groups for all comparisons.

The clinical and the pathologic parameters are listed in Table 2. Although a certain trend of longer operation time and increased estimated blood loss was seen in the older groups, the differences did not reach a statistically significant level for any of the three comparisons. The tumors were significantly larger in the older groups for all comparisons; however, the proportions of TNM stages for the tumors were significantly different only in the com-

Table 3. Postoperative complications $(n=578)$

\begin{tabular}{|c|c|}
\hline Postoperative complication & No. $(\%)$ \\
\hline No. of patient who developed postoperative complications & $122(21.1)$ \\
\hline \multicolumn{2}{|l|}{ Complication details } \\
\hline lleus & $30(5.2)$ \\
\hline Chylous ascites & $29(5.0)$ \\
\hline Urinary retention/urinary tract infection & $25(4.3)$ \\
\hline Wound infection/seroma & $13(2.2)$ \\
\hline Anastomosis leakage & $9(1.6)$ \\
\hline Pleural effusion/pneumonia & $6(1.0)$ \\
\hline Brachial nerve palsy & $4(0.7)$ \\
\hline Ureter injury & $3(0.5)$ \\
\hline Deep surgical site infection & $3(0.5)$ \\
\hline Delirium & $3(0.5)$ \\
\hline Arrhythmia & $2(0.3)$ \\
\hline Anastomosis bleeding & $2(0.3)$ \\
\hline Intraabdominal bleeding & $2(0.3)$ \\
\hline Cerebral infarction & $2(0.3)$ \\
\hline Uncontrolled ascites & $2(0.3)$ \\
\hline Peptic ulcer bleeding & $2(0.3)$ \\
\hline Hepatic failure & $2(0.3)$ \\
\hline Strangulated ileostomy site herniation & $1(0.2)$ \\
\hline Bleeding from Mallory-Weiss syndrome & $1(0.2)$ \\
\hline Seizure & $1(0.2)$ \\
\hline Small bowel infarction & $1(0.2)$ \\
\hline Deep vein thrombosis & $1(0.2)$ \\
\hline \multicolumn{2}{|l|}{ Clavien-Dindo classification } \\
\hline । & $34(5.9)$ \\
\hline$\|$ & $64(11.1)$ \\
\hline III & $18(3.1)$ \\
\hline IV & $6(1.0)$ \\
\hline Reoperation, yes & $12(2.1)$ \\
\hline Operative mortality, yes & $4(0.7)$ \\
\hline
\end{tabular}

parison with a cutoff value of 70 years.

The overall postoperative complication rate was $21.1 \%$ ( $\mathrm{n}=$ 122). Table 3 shows the details and the severities of the postoperative complications. Ileus was the most common complication after a laparoscopic resection of colorectal cancer. Most of the complications were grade I/II $(\mathrm{n}=98,17.0 \%)$ and were treated with conservative management. Of the patients, $4.2 \%$ suffered from grade III/IV complication. Twelve patients $(2.1 \%)$ required reoperation to control the complication. There were 4 cases of operative mortality $(0.7 \%)$.

Postoperative recovery, including a return to normal bowel movements and resumption of oral intake, was slightly delayed in the older groups (Table 4). However, the differences in return to normal bowel movements were not statistically significant for any of the comparisons. The time taken to resume oral intake was significantly delayed in the older groups with cutoffs at 70 and 75 years, but the differences were not statistically significant when compared with the cutoff at 80 years. Postoperative hospital stay was significantly delayed in all comparisons with all three thresholds. Postoperative complication rates were consistently higher in older groups in all three cutoff categories; however, only a comparison with an 80-year cutoff showed a statistically significant difference between the younger and older groups. A trend of an advanced grade of complication according to the Clavien-Dindo classification was noted, but only the comparison with an 80-year cutoff showed a significant difference between the younger and the older groups.

In the univariate analysis with a logistic regression model, age $\geq$ 80 years emerged as the only significant risk factor associated with the development of postoperative complications (OR, 2.5; 95\% CI, 1.182-5.324; $\mathrm{P}=0.017$ ) (Table 5). Because no other significant factors were found in the univariate analysis, a multivariate analysis was conducted using all other parameters. Age $\geq 80$ years remained a significant risk factor (OR, 3.0; 95\% CI, 1.296-7.123; P $=0.011$ ). Age $\geq 70$ and age $\geq 75$ years were not significant risk factors for postoperative complications in the multivariate analyses for any combination of variables (data not shown).

\section{DISCUSSION}

The average human life span in many developed countries continues to increase. This is a worldwide phenomenon, and Korea is no exception. According to a recent government report, the average life span of Koreans was 81.9 years in 2013 [9]. Cancer is particularly a disease of older individuals, and its incidence rises with age. In 2012, the incidence of colorectal cancer in those aged 80 84 years was twice that in those aged 60-64 years for both genders; consequently, operations for elderly patients with colorectal cancer have become more frequent in recent years. Although it is well documented that postoperative morbidity and mortality rates are likely to be increased in elderly patients, major procedures in that population are hard to avoid because a resection is the only 
Table 4. Postoperative outcomes of the patients according to the different age cutoffs

\begin{tabular}{|c|c|c|c|c|c|c|c|c|c|}
\hline \multirow[b]{2}{*}{ Variable } & \multicolumn{3}{|c|}{ Cutoff age 70} & \multicolumn{3}{|c|}{ Cutoff age 75} & \multicolumn{3}{|c|}{ Cutoff age 80} \\
\hline & $\begin{array}{c}<70 \\
(\mathrm{n}=383)\end{array}$ & $\begin{array}{c}\geq 70 \\
(n=195)\end{array}$ & P-value & $\begin{array}{c}<75 \\
(\mathrm{n}=480)\end{array}$ & $\begin{array}{c}\geq 75 \\
(\mathrm{n}=98)\end{array}$ & P-value & $\begin{array}{c}<80 \\
(n=547)\end{array}$ & $\begin{array}{c}\geq 80 \\
(n=31)\end{array}$ & P-value \\
\hline Time to first bowel movement (day) & $3.3 \pm 1.7$ & $3.4 \pm 1.4$ & 0.218 & $3.3 \pm 1.6$ & $3.5 \pm 1.5$ & 0.084 & $3.3 \pm 1.6$ & $3.4 \pm 1.5$ & 0.465 \\
\hline Time to resume oral intake (day) & $3.0 \pm 1.9$ & $3.2 \pm 1.3$ & 0.019 & $3.0 \pm 1.8$ & $3.3 \pm 1.3$ & 0.012 & $3.1 \pm 1.8$ & $3.3 \pm 1.2$ & 0.254 \\
\hline Postoperative hospital stay (day) & $11.2 \pm 6.8$ & $12.4 \pm 8.0$ & 0.011 & $11.3 \pm 6.7$ & $13.2 \pm 9.4$ & 0.002 & $11.3 \pm 6.8$ & $16.0 \pm 12.0$ & 0.002 \\
\hline Complications, yes & $72(18.8)$ & $50(25.6)$ & 0.057 & $96(20.0)$ & $26(26.5)$ & 0.149 & $110(20.1)$ & $12(38.7)$ & 0.014 \\
\hline Clavien-Dindo classification & & & $0.060^{\mathrm{a}}$ & & & 0.149 & & & $0.015^{\mathrm{a}}$ \\
\hline I & $26(6.8)$ & $8(4.1)$ & & $30(6.2)$ & $4(4.1)$ & & $33(6.0)$ & $1(3.2)$ & \\
\hline$\|$ & $31(8.1)$ & $33(16.9)$ & & $46(9.6)$ & $18(18.4)$ & & $56(10.2)$ & $8(25.8)$ & \\
\hline III & $14(3.7)$ & $4(2.1)$ & & $15(3.1)$ & $3(3.1)$ & & $16(2.9)$ & $2(6.5)$ & \\
\hline IV & $1(0.3)$ & $5(2.6)$ & & $5(1.0)$ & $1(1.0)$ & & $5(0.9)$ & $1(3.2)$ & \\
\hline Operative mortality, yes & $1(0.3)$ & $3(1.5)$ & 0.114 & $4(0.8)$ & $0(0)$ & 1.000 & $4(0.7)$ & $0(0)$ & 1.000 \\
\hline
\end{tabular}

Values are presented as mean \pm standard deviation or number $(\%)$.

aModified P-value.

Table 5. Univariate and multivariate analyses by using a logistic regression model to find risk factors for postoperative complication

\begin{tabular}{|c|c|c|c|c|c|c|c|c|c|}
\hline \multirow{2}{*}{ Variable } & \multirow{2}{*}{$\begin{array}{l}\text { Complication (-) } \\
\quad(\mathrm{n}=456)\end{array}$} & \multirow{2}{*}{$\begin{array}{l}\text { Complication }(+) \\
\quad(n=122)\end{array}$} & \multirow{2}{*}{ P-value } & \multicolumn{3}{|c|}{ Univariate } & \multicolumn{3}{|c|}{ Multivariate } \\
\hline & & & & $\mathrm{OR}$ & $95 \% \mathrm{Cl}$ & P-value & $\mathrm{OR}$ & $95 \% \mathrm{Cl}$ & P-value \\
\hline \multicolumn{10}{|l|}{ Age (yr) } \\
\hline$\geq 70$ & $145(31.8)$ & $50(41.0)$ & 0.057 & 1.5 & $0.987-2.247$ & 0.058 & - & - & - \\
\hline$\geq 75$ & $72(15.8)$ & $26(21.3)$ & 0.149 & 1.4 & $0.875-2.384$ & 0.150 & - & - & - \\
\hline$\geq 80$ & $19(4.2)$ & $12(9.8)$ & 0.014 & 2.5 & $1.182-5.324$ & 0.017 & 3.0 & $1.296-7.123$ & 0.011 \\
\hline Female sex & $273(59.9)$ & $80(65.6)$ & 0.251 & 1.3 & $0.841-1.939$ & 0.252 & 1.1 & $0.713-1.740$ & 0.637 \\
\hline Body mass index $\left(\mathrm{kg} / \mathrm{m}^{2}\right)$ & $23.7 \pm 3.3$ & $23.4 \pm 3.7$ & 0.206 & 1.0 & $0.920-1.035$ & 0.417 & 1.0 & $0.922-1.049$ & 0.620 \\
\hline \multicolumn{10}{|l|}{ ASA } \\
\hline$\geq 2$ & $302(66.2)$ & $81(66.4)$ & 0.973 & 1.0 & $0.660-1.538$ & 0.973 & - & - & - \\
\hline$\geq 3$ & $80(17.5)$ & $27(22.1)$ & 0.247 & 1.3 & $0.818-2.182$ & 0.248 & 1.1 & $0.614-1.880$ & 0.802 \\
\hline Comorbidities, yes & $249(54.6)$ & $59(56.6)$ & 0.700 & 1.1 & $0.724-1.619$ & 0.700 & - & - & - \\
\hline No. of comorbidities & $0.9 \pm 1.0$ & $1.0 \pm 1.0$ & 0.411 & 1.1 & $0.907-1.340$ & 0.328 & - & - & - \\
\hline Operation name, LAR and APR & $172(37.7)$ & $51(41.8)$ & 0.410 & 1.2 & $0.790-1.781$ & 0.411 & 1.1 & $0.677-1.699$ & 0.766 \\
\hline Laparoscopy method, HALS & $317(69.5)$ & $94(77.0)$ & 0.103 & 1.5 & $0.923-2.348$ & 0.104 & 1.7 & $0.974-2.875$ & 0.062 \\
\hline Operation time & $141.5 \pm 38.2$ & $145.2 \pm 53.9$ & 0.748 & 1.0 & $0.997-1.008$ & 0.397 & 1.0 & 0.998-1.009 & 0.182 \\
\hline Estimated blood loss & $154.1 \pm 216.9$ & $189.7 \pm 263.4$ & 0.279 & 1.0 & $1.000-1.001$ & 0.136 & 1.0 & $1.000-1.001$ & 0.305 \\
\hline Conversion, yes & $3(0.7)$ & $2(1.6)$ & 0.285 & 2.5 & $0.416-15.232$ & 0.315 & 3.6 & $0.464-28.355$ & 0.220 \\
\hline No. of retrieved lymph nodes & $23.0 \pm 13.0$ & $22.5 \pm 10.5$ & 0.610 & 1.0 & $0.981-1.013$ & 0.997 & 1.0 & $0.984-1.021$ & 0.830 \\
\hline Tumor size (cm) & $5.0 \pm 2.3$ & $4.8 \pm 2.6$ & 0.203 & 1.0 & $0.884-1.037$ & 0.286 & 0.9 & $0.844-1.037$ & 0.205 \\
\hline \multicolumn{10}{|l|}{ TNM stage } \\
\hline III/IV & $220(49.2)$ & 55 (45.8) & 0.510 & 0.9 & 0.583-1.308 & 0.510 & 0.9 & $0.570-1.360$ & 0.567 \\
\hline IV & $31(6.9)$ & $6(5.0)$ & 0.446 & 0.7 & $0.288-1.734$ & 0.706 & - & - & - \\
\hline
\end{tabular}

Values are presented as number (\%) or mean \pm standard deviation.

$\mathrm{OR}$, odds ratio; $\mathrm{Cl}$, confidence interval; ASA, American Society of Anesthesiologists; LAR, low anterior resection; APR, abdominoperineal resection; HALS, hand-assisted laparoscopic surgery. 
optimal curative treatment for colorectal cancer and is frequently required to resolve obstructive symptoms, even in palliative cases.

In the 1960s, abdominal surgery for elderly patients was considered to be hazardous. An age over 80 years was a contraindication for a major resection, and the postoperative morbidity and mortality rates were high. However, with better understanding of the physiological changes in older people, developments in anesthesiology techniques, improvements in the ability to monitor and manage comorbidities, comprehensive perioperative care, and innovations in surgery, such as laparoscopy, the postoperative outcome for older patients undergoing surgery for colorectal cancer has improved gradually $[3,10,11]$.

Studies on the management of colorectal surgery in elderly patients are expanding rapidly. Several studies have suggested that age alone is not a risk factor for postoperative compromised outcomes after a major colorectal procedure, especially in the era of laparoscopy, but rather the comorbidities that are commonly found in older people are [4, 11-16]. Nevertheless, controversy continues because others have reported a somewhat higher complication rate and a longer hospital stay in elderly patients [7, 1721]. That elderly patients usually have a higher risk profile is true $[17,22]$, and this might influence the postoperative outcomes; however, even without significant comorbidity, aged people may be frail. This frailty, which is a result of deteriorations in the overall physiological capacity and of decreased vitality, may be the primary risk factors for an unfavorable postoperative outcome, which cannot be explained by the absence of a definite accompanying disease. Identifying this 'frail' subset might help to stratify the surgical risk for 'elderly' patients and enable better comprehensive care for the relevant population. The problem is that the term 'elderly' is a very subjective term. The cutoff is quite relative and variable. The World Health Organization defined 'elderly' as being older than 65 years of age. However, in industrialized or industrializing countries, where a prolonged lifespan is common, medically significant thresholds for 'elderly' seem to be increasing. Therefore, many studies use 70 years or 75 years, or even 80 years, as cutoffs. However, the evidence upon which these definitions are based is unknown.

In this study, we compared the postoperative clinical outcomes between 'younger' and 'older' groups with three different thresholds to determine how age might affect postoperative outcomes. As expected, we observed a higher prevalence of comorbid conditions and higher ASA scores in the older groups. Parameters associated with postoperative recovery, including the times taken to return to normal bowel movements and oral intake, were delayed in older groups. However, the gaps between any two groups were too small to have clinical meaning and even to do statistically significant comparisons (e.g., the time to resume oral intake with cutoff ages of 70 and 75 years). However, postoperative hospital stays were significantly prolonged in the older groups for all three cutoffs, and the gap increased as the cutoff value increased.

In the univariate and the multivariate analyses, age over 80 was the only significant risk factor out of all the variables. Cutoffs ages of 70 and 75 were not significant risk factors for compromised postoperative morbidity. This finding is similar to those of previous studies. Bircan et al. [7] reported increased complication rates only in patients older than 80 , compared with groups younger than 70 or 70-75 years of age. Moreover, most studies that have adopted an age of greater than 80 as the cutoff value for defining 'elderly' have demonstrated consistently that older age is an independent risk factor for worse short-term outcomes after colorectal surgery.

This study has some limitations. Although our database was maintained prospectively, this was a retrospective review, so we cannot exclude the possibility of bias. As the cutoff value was increased, the differences in numbers between the groups also increased. The number of patients older than 80 was small, so this might have affected the statistics.

In conclusion, we have documented that age $>80$ years can be a risk factor for compromised postoperative outcomes after laparoscopic colorectal surgery while age $>70$ or age $>75$ years is not. Thus, special care should be taken during perioperative periods while treating these 'oldest old' patients. However, to confirm this finding, further studies with larger populations or meta-analyses should be conducted to achieve more robust evidence.

\section{CONFLICT OF INTEREST}

No potential conflict of interest relevant to this article was reported.

\section{REFERENCES}

1. Jung KW, Won YJ, Kong HJ, Oh CM, Cho H, Lee DH, et al. Cancer statistics in Korea: incidence, mortality, survival, and prevalence in 2012. Cancer Res Treat 2015;47:127-41.

2. Lemmens VE, Janssen-Heijnen ML, Houterman S, Verheij KD, Martijn H, van de Poll-Franse L, et al. Which comorbid conditions predict complications after surgery for colorectal cancer? World J Surg 2007;31:192-9.

3. Watters JM. Surgery in the elderly. Can J Surg 2002;45:104-8.

4. Bottino V, Esposito MG, Mottola A, Marte G, Di Maio V, Sciascia $\mathrm{V}$, et al. Early outcomes of colon laparoscopic resection in the elderly patients compared with the younger. BMC Surg 2012;12 Suppl 1:S8.

5. Weber DM. Laparoscopic surgery: an excellent approach in elderly patients. Arch Surg 2003;138:1083-8.

6. Pelloni A. Colorectal surgery in patients over 80 years old. Hepatogastroenterology 2012;59:120-3.

7. Bircan HY, Koc B, Ozcelik U, Adas G, Karahan S, Demirag A. Are there any differences between age groups regarding colorectal surgery in elderly patients? BMC Surg 2014;14:44.

8. Clavien PA, Barkun J, de Oliveira ML, Vauthey JN, Dindo D, Schulick RD, et al. The Clavien-Dindo classification of surgical 
complications: five-year experience. Ann Surg 2009;250:187-96.

9. Statistics Korea [Internet]. Daejeon: Statistics Korea; 2015 [cited 2015 Sep 5]. Available from: http://kosis.kr.

10. Hamaker ME, Schiphorst AH, Verweij NM, Pronk A. Improved survival for older patients undergoing surgery for colorectal cancer between 2008 and 2011. Int J Colorectal Dis 2014;29:1231-6.

11. Makela JT, Kiviniemi H, Laitinen S. Survival after operations for colorectal cancer in patients aged 75 years or over. Eur J Surg 2000; 166:473-9.

12. Inoue Y, Kawamoto A, Okugawa Y, Hiro J, Saigusa S, Toiyama Y, et al. Efficacy and safety of laparoscopic surgery in elderly patients with colorectal cancer. Mol Clin Oncol 2015;3:897-901.

13. Basili G, Lorenzetti L, Biondi G, Preziuso E, Angrisano C, Carnesecchi P, et al. Colorectal cancer in the elderly. Is there a role for safe and curative surgery? ANZ J Surg 2008;78:466-70.

14. Fiscon V, Portale G, Migliorini G, Frigo F. Laparoscopic resection of colorectal cancer in elderly patients. Tumori 2010;96:704-8.

15. Khan MR, Bari H, Zafar SN, Raza SA. Impact of age on outcome after colorectal cancer surgery in the elderly - a developing country perspective. BMC Surg 2011;11:17.

16. Jeong DH, Hur H, Min BS, Baik SH, Kim NK. Safety and feasibility of a laparoscopic colorectal cancer resection in elderly patients. Ann Coloproctol 2013;29:22-7.
17. Marusch F, Koch A, Schmidt U, Steinert R, Ueberrueck T, Bittner R, et al. The impact of the risk factor "age" on the early postoperative results of surgery for colorectal carcinoma and its significance for perioperative management. World J Surg 2005;29:1013-21.

18. Fiscon V, Portale G, Frigo F, Migliorini G. Laparoscopic resection of colorectal cancer: matched comparison in elderly and younger patients. Tech Coloproctol 2010;14:323-7.

19. Grosso G, Biondi A, Marventano S, Mistretta A, Calabrese G, Basile F. Major postoperative complications and survival for colon cancer elderly patients. BMC Surg 2012;12 Suppl 1:S20.

20. Neuman HB, Weiss JM, Leverson G, O'Connor ES, Greenblatt DY, Loconte NK, et al. Predictors of short-term postoperative survival after elective colectomy in colon cancer patients $\geq 80$ years of age. Ann Surg Oncol 2013;20:1427-35.

21. Al-Refaie WB, Parsons HM, Habermann EB, Kwaan M, Spencer MP, Henderson WG, et al. Operative outcomes beyond 30-day mortality: colorectal cancer surgery in oldest old. Ann Surg 2011; 253:947-52.

22. Kristjansson SR, Nesbakken A, Jordhoy MS, Skovlund E, Audisio RA, Johannessen HO, et al. Comprehensive geriatric assessment can predict complications in elderly patients after elective surgery for colorectal cancer: a prospective observational cohort study. Crit Rev Oncol Hematol 2010;76:208-17. 